\title{
The benefit of a vascular access specialist placing a peripheral intravenous catheter: a narrative review of the literature
}

\author{
${ }^{*}$ Nicole Marsh ${ }^{1,2,3,4}$, Emily Larsen ${ }^{1,2,3}$, GDipHlthRes, Joan Webster ${ }^{1,3}$, Marie Cooke ${ }^{1,2,3}$, Claire M Rickard ${ }^{1,2,3}$ \\ 'Nursing \& Midwifery Research Centre, Royal Brisbane and Women's Hospital, QLD, Australia \\ ${ }^{2}$ School of Nursing and Midwifery, Griffith University, QLD, Australia \\ ${ }^{3}$ Alliance for Vascular Access Teaching and Research, Menzies Health Institute Queensland, QLD, Australia \\ ${ }^{4}$ School of Nursing, Queensland University of Technology, Kelvin Grove, QLD, Australia \\ *Corresponding author \\ Nicole Marsh, RN, PhD., Nursing and Midwifery Director, Research, Royal Brisbane and Women's Hospital, Butterfield Street, Herston, \\ QLD 4029, Australia \\ Email nicole.marsh@health.qld.gov.au
}

Keywords intravenous, vascular access devices, phlebitis, vascular access specialist

For referencing Marsh $\mathrm{N}$ et al. The benefit of a vascular access specialist placing a peripheral intravenous catheter: a narrative review of the literature. Vascular Access 2020; 6(1):10-15.

Dol https://doi.org/10.33235/va.6.1.10-15

\begin{abstract}
Background Peripheral intravenous catheters (PIVCS) are a quick, effective means to gain access to a patient's vasculature for the delivery of intravenous treatment. Although a frequently performed procedure, the skill and training for clinical staff to successfully place these catheters is often underestimated, with up to $50 \%$ of insertions requiring multiple attempts prior to successful placement.

Methods A narrative review of studies describing the benefit of vascular access specialists (VAS) inserting PIVCS was undertaken. A detailed literature search was conducted in the Cochrane Central Register of Controlled Trials (CENTRAL), PubMed, and EMBASE, on 30 November 2018. The methodological rigour of included studies was assessed as per the Mixed Methods Appraisal Tool (MMAT).

Results The search generated 708 records. Once titles, abstracts and reference lists were screened, 10 studies were included in this review. Six studies compared a VAS team with insertion by other health professionals; four examined outcome improvements within their own VAS team. Outcomes considered included: PIVC failure; phlebitis; PIVC-related infection; and first-time insertion success. All included studies described positive VAS team outcomes; however, methods and results reporting varied greatly in outcome assessment and quality. Overall, the quality assessment of included studies (using the MMAT) was low, with 68\% of criteria items scoring 'not reported' or unclear.
\end{abstract}

Conclusion Use of a VAS for PIVC insertion to reduce PIVC failure and improve first-time insertion success is currently inadequately supported by high quality evidence. Well conducted randomised control trials (RCTs) to compare VAS with the generalist PIVC insertion model are required.

\section{INTRODUCTION}

Placing a peripheral intravenous catheter (PIVC) is a quick and effective means to gain access to a patient's vasculature for the delivery of intravenous (IV) treatment.1.2 Unfortunately, for such an important medical device, they have an alarming failure rate, reported to be as high as 69\%.2-4 Many risk factors associated with PIVC failure can be directly related to the insertion of the catheter itself (e.g. the choice of catheter gauge and insertion site) ${ }^{5-8}$ it is therefore anticipated that the inserting clinician determining these factors may have an impact on successful catheter placement. Although PIVC placement is the most frequently performed invasive procedure in hospitals, ${ }^{9}$ the skill and training for clinical staff to successfully place a catheter is often underestimated, with up to $50 \%$ of insertions requiring multiple attempts prior to successful placement. 2,10,11

Different models for insertion are used by different healthcare facilities. Some hospitals have PIVC insertions conducted at the bedside by generalist clinicians (nurses and doctors with 
varying skill levels and job descriptions). ${ }^{12}$ This approach focuses on the short-term goal of achieving PIVC placement, with an underlying belief that a lack of specific expertise rarely has negative outcomes, ${ }^{13}$ such as subsequent PIVC failure. Other hospitals employ vascular access specialists (VAS), often nurses, ${ }^{14}$ either as part of a dedicated team ${ }^{15}$ or within the existing nursing framework ${ }^{16}$ for PIVC insertion and clinician education. It is thought that their higher level and more specific expertise enhances patient care, decreases the incidence of infusion complications, and ultimately saves costs associated with clinician time, materials, and length of hospital stay. ${ }^{16}$

Vascular access specialist teams, often referred to as infusion therapy or intravenous therapy teams, ${ }^{17}$ are centrally structured within a healthcare facility. It is believed that by freeing these specialised nurses from other responsibilities, it allows them to focus on providing accurate PIVC insertion, eliminates or reduces waiting lists, and provides consistency and safe delivery of all infusion services. ${ }^{14,18,19}$ Other healthcare models incorporate VAS as part of their existing nursing workforce. ${ }^{16}$ These nurses have extensive training and education about PIVC insertion and care, and assist with PIVC placements and troubleshoot any infusionrelated concerns or PIVC complications within their clinical setting. ${ }^{16}$ This model is thought to improve patient outcomes by reducing PIVC-related complications, as well as offer cost savings benefits for the healthcare institution, because an additional labour force is not required. ${ }^{16}$

Nevertheless, there is a paucity of evidence from clinical trials to support the benefit of VAS PIVC insertions. A recent Cochrane systematic review that examined VAS team insertions, of any vascular access device type, for the prevention of failure, found no randomised controlled trial (RCT) had been conducted in this area. ${ }^{17}$ Since this review, one pilot RCT has compared the generalist inserter with a VAS. ${ }^{2}$ This trial reported a higher failure rate with generalist inserted PIVCs $(27 / 50,54 \%)$ than those inserted by a VAS (33/69, 48\%). ${ }^{2}$ However, this study was not powered to show a statistically significant difference, rather to test the feasibility of conducting a large multicentre RCT testing PIVC insertion models.

As there is a paucity of clinical trials examining the advantage of VAS inserted PIVCs, this review compared studies of varying designs to explore the benefit of a VAS in preventing PIVC complications and failure.

\section{DESCRIPTION OF A VAS}

A VAS is typically defined as a clinician who has advanced knowledge and skills to place and manage vascular access devices. ${ }^{12}$ These specialists have superior patient assessment skills and advanced knowledge of vascular access technology, including catheter design, insertion assistive devices such as ultrasound, and related products including dressings and securement devices. ${ }^{2}$

\section{METHODS}

A narrative review was undertaken to synthesise the accumulated state of knowledge of the benefit of a VAS inserting PIVCs. The review was conducted using criteria established by Green et al. ${ }^{20}$ As this review included studies of various designs, critical appraisal was undertaken using the Mixed Methods Appraisal Tool (MMAT). ${ }^{21}$

\section{Description of the intervention}

The intervention under consideration is placing PIVCs by a VAS to reduce the incidence of PIVC failure and complications.

\section{Search methods for identification of studies}

A detailed literature search was conducted in the Cochrane Central Register of Controlled Trials (CENTRAL), PubMed, and EMBASE, on 30 November 2018, to identify the benefit of a VAS for PIVC insertion. Medical subject headings (MeSH) terms and descriptors included: catheterisation, peripheral; catheters, indwelling; team; clinician; and specialist. A reference list of included studies was added to identify any other studies to be incorporated in the review.

\section{Data collection and data analysis}

Two review authors independently screened, extracted data and performed quality assessment of the included studies.

\section{RESULTS}

The search generated 708 records. The flowchart in Figure 1 identifies the reasons for inclusion and exclusion and is formatted in accordance with the Preferred Reporting Items for Systematic Reviews and Meta-Analyses (PRISMA) checklist. ${ }^{22}$ Titles and abstracts were searched for relevant papers; once duplicates were removed, four papers ${ }^{15,23-25}$ included information about expert PIVC inserters. The reference lists of included papers were searched, and an additional six papers were retrieved. ${ }^{16,26-30}$ The research reported in this review was from studies predominantly conducted in the United States of America (USA) and included a quasi-randomised control trial ${ }^{29}$ and descriptive observational studies $^{15,16,23-29}$ (see Table 1).

Soifer et al. ${ }^{30}$ compared PIVC insertions by a VAS team (Monday to Friday in business hours) with insertions by medical house staff (week days between $5 \mathrm{pm}$ and 9am, and weekends) in relation to PIVC complication rates. This quasi-randomised control trial reported an almost 14\% lower occurrence of local complications (tenderness, warmth, erythema, swelling, and palpable cord) with VAS-inserted catheters (VAS, $n=58 / 737,7.9 \%$; junior medical staff, $n=30 / 138,21.7 \%)$. This study reported no PIVC-related bacteraemia in the VAS group compared to three cases out of 138 PIVCs (2\%) inserted by junior medical staff. ${ }^{30}$

Tomford et al. ${ }^{25}$ conducted a prospective observational study where four clinical units introduced PIVC insertion by a VAS team. The researchers staggered each unit's commencement 
date by 10 days; the controls were patients from units awaiting introduction of the VAS team. Phlebitis decreased 17\% $(p<0.001)$ with VAS-inserted PIVCs ( $n=63 / 433,15 \%)$ compared with the control, which was medical house staff-inserted PIVCs $(n=136 / 427,32 \%)^{25}$

Palefski and Stoddard ${ }^{16}$ compared PIVC insertions by a VAS, within an existing nursing framework, with generalist nurseinsertions. They reported a 16\% $(p<0.001)$ lower PIVC failure rate with VAS-inserted catheters (VAS, $n=126 / 639$, 19.7\%; generalist nurse, $n=49 / 137,35.8 \%$ ) and, for a patient's first PIVC per hospital admission, there was a lower incidence of pain on infusion (VAS, $n=5 / 319,1.6 \%$; generalist nurse, $n=4 / 123,3.3 \%$ ), phlebitis (VAS $n=8 / 319,2.5 \%$; generalist nurse $n=6 / 123,4.9 \%$ ), and a longer PVC dwell time (VAS 2.2 days; generalist nurse 2.0 days). ${ }^{16}$

In a descriptive study by Scalley et al. ${ }^{24}$ members of the VAS team, as part of their usual practice, inspected the PIVC sites of hospitalised patients daily. In clinical areas PIVCs were inserted by members of the VAS team, ward nurses, anaesthesiologists, nurse anaesthetists, paramedics and medical staff. As this was a descriptive study, patients were not allocated to have their PIVC placed by a particular health professional. If an incidence of phlebitis was identified, the VAS team member graded the phlebitis severity. Phlebitis was reported as 3\% lower ( $p=0.05 \%)$ for VAS-inserted catheters (8.8\%) compared to those inserted by other health professionals (11.8\%). ${ }^{24}$ This study included 31,115 PIVCs, but did not identify the number of PIVCs inserted by the VAS team compared to other health professionals.

Miller et al. ${ }^{29}$ conducted a descriptive study that reported PIVCrelated bloodstream infection (BSI) occurrences after the first year of a VAS team in their hospital. They found an almost 3-fold decrease (45 to 16 cases) in infections, (4.6 per 1000 discharges to 1.5 per 1000 discharges) with a VAS team placing catheters.

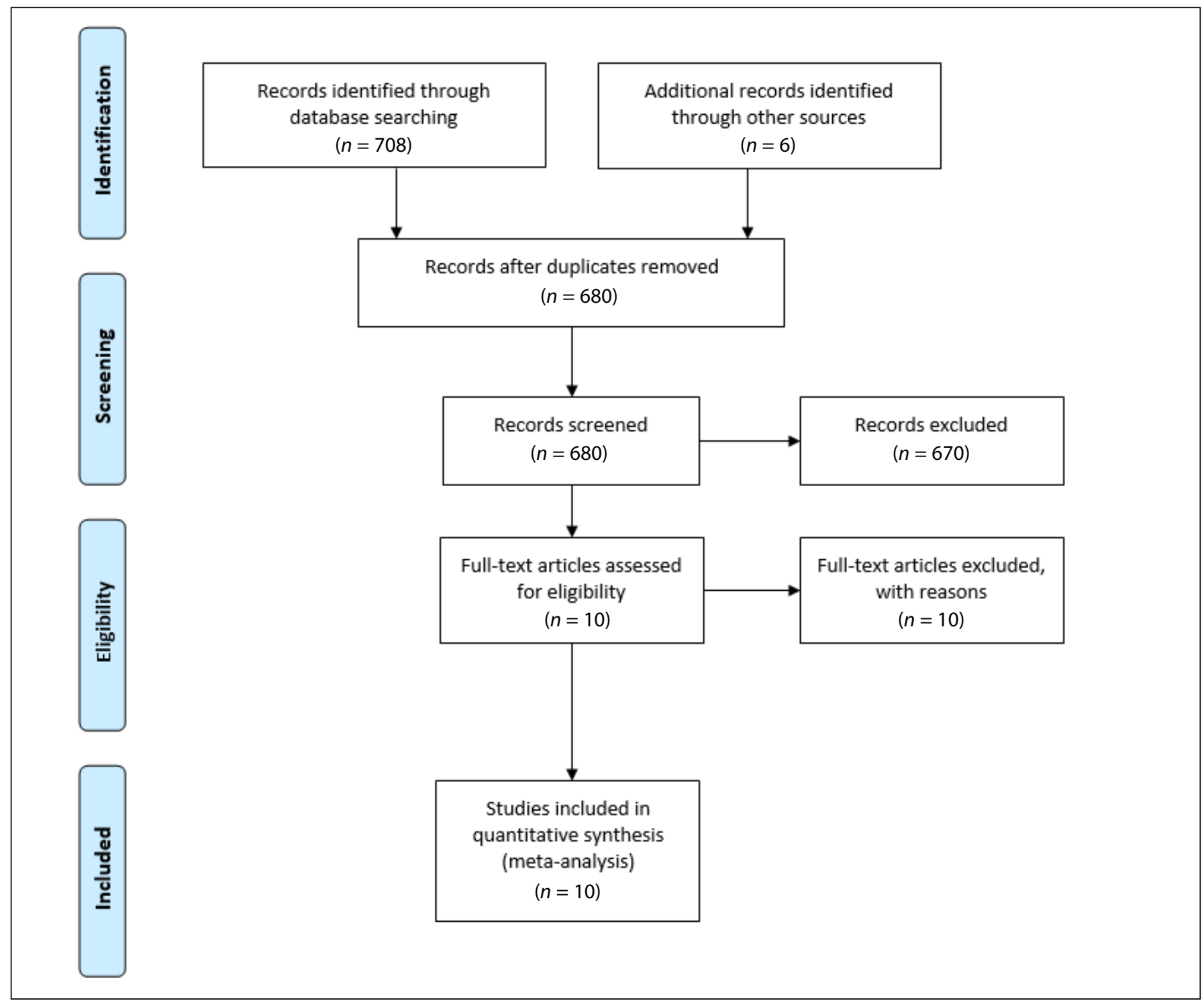

Figure 1. PRISMA flowchart of included studies 
Similarly, Meier et al..$^{28}$ reported a decrease in primary BSI of 35\% (1.1 per 1000 patient-days reduced to 0.7 per 1000 patientdays) with the introduction of a VAS team. Meier et al. ${ }^{28}$ also reported a decrease in primary nosocomial BSI of 35\% (1.1 to 0.7 per 1000 patient-days); this encompassed a 51\% reduction in primary nosocomial BSI with Staphylococcus aureus (0.33 to 0.16\% infections per 1000 patient-days).

Two descriptive studies identified the benefits of the introduction of a VAS team but did not compare data with another insertion model. ${ }^{15,27}$ Carr et al. ${ }^{15}$ reported that during the first five months of establishing a VAS team, there was an improvement in firstattempt PIVC insertion success from an estimated $40 \%$ to $98 \%$. DaSilva et al. ${ }^{27}$ reported a $5 \%$ increase in the use of smaller 24 -gauge catheters (16.5\% to $21.6 \%$ ) and an overall decrease in the number of PIVCs insertions (2.12 catheters per patient to 1.57 catheter per patient) with the introduction of a VAS team.

Bosma and Jewesson ${ }^{26}$ randomly selected 250 patients who had PIVC placements by their VAS team to describe the characteristics of their VAS service. This study reported that most consults were for surgical patients and that 39\% of patients were graded as having poor vein status. Finally, a descriptive study by Hunter ${ }^{23}$ reported that a new VAS service led to a reduction in the number of PIVC insertion attempts (from six to a maximum of two) and PIVC complications (phlebitis rates dropped 2\%) compared to PIVC insertions by ward nurses.

\section{Quality assessment}

Overall, the methodological quality of the included studies was generally poor. Justification of the sampling strategy and sample representation of the target population was only provided in two studies. ${ }^{15,25}$ Three studies did not clearly define their measurements ${ }^{23,27,230}$ and only five studies clearly outlined a statistical analysis appropriate for the research question. 15,16,24-26 All included studies had a risk of non-response bias.

\section{DISCUSSION}

Studies in this review reported various outcomes including firsttime insertion success, ${ }^{15}$ PIVC-related complications, ${ }^{16,30}$ and/or the number of PIVC insertions. ${ }^{27}$ Although the methodology and outcomes varied, all reported a benefit with the use of a VAS. However, five of the 10 studies included were conducted before the year $2000,{ }^{24,25,28-30}$ making it difficult to determine whether advancements in infusion therapy, such as new catheter materials and designs, ${ }^{10,31}$ dressings and securements, ${ }^{32-34}$ or the use of insertion assistance devices such as ultrasound, ${ }^{35,36}$ would impact PIVC failure rates. In addition, over the last 10 years, there has also been increased use of different vascular access devices such as midlines and peripherally inserted central catheters. ${ }^{37-39}$ These devices are often used for patients with IV treatment expected to last for greater than one week or for patients with difficult vascular access. ${ }^{38}$ Therefore, the increased use of such devices may have impacted upon the incidence of PIVC failure reported in recent studies compared with their older counterparts.

Table 1. Characteristics of included studies

\begin{tabular}{|c|c|c|c|c|c|}
\hline $\begin{array}{l}\text { Author } \\
\text { (year) }\end{array}$ & State/Country & Setting & $\begin{array}{l}\text { VAS team } \\
\text { (label) }\end{array}$ & Comparison & Outcome measure \\
\hline Bosma (2002) & $\begin{array}{l}\text { British Columbia, } \\
\text { Canada }\end{array}$ & $\begin{array}{l}\text { Single centre; non-critical } \\
\text { medical and surgical wards }\end{array}$ & 'Infusion nurses' & Not applicable & $\begin{array}{l}\text { Number of consultations; } \\
\text { successful PIVC insertion }\end{array}$ \\
\hline Carr (2010) & Galway, Ireland & Single centre; hospital wide & $\begin{array}{l}\text { IV 'Cannulation } \\
\text { 'Team }\end{array}$ & $\begin{array}{l}\text { Pre-post commencement } \\
\text { of IV Cannulation Team }\end{array}$ & First-time insertion success \\
\hline Da Silva (2010) & Sau Paulo, Brazil & $\begin{array}{l}\text { Single centre; medical, } \\
\text { surgery, haematology and } \\
\text { oncology units }\end{array}$ & 'IV Team' & $\begin{array}{l}\text { Pre-post commencement } \\
\text { of IV Team }\end{array}$ & $\begin{array}{l}\text { First-time insertion success; } \\
\text { number of PIVCs; phlebitis }\end{array}$ \\
\hline Hunter (2003) & Wisconsin, USA & $\begin{array}{l}\text { Single centre (Phase 2); } \\
\text { medical and surgical wards }\end{array}$ & $\begin{array}{l}\text { 'Vascular Access } \\
\text { Team' }\end{array}$ & Unclear & $\begin{array}{l}\text { PIVC-related complication; } \\
\text { number of insertion attempts }\end{array}$ \\
\hline Palefski (2001) & Unknown, USA & $\begin{array}{l}\text { Multi-centre; hospital wide, } \\
\text { 'infusion centre'; and patients' } \\
\text { homes }\end{array}$ & 'Infusion nurse' & Generalist nurse & PIVC-related complications \\
\hline Meier (1998) & Iowa, USA & $\begin{array}{l}\text { Single centre; acute and } \\
\text { critical care wards }\end{array}$ & 'Specialised IV Team' & $\begin{array}{l}\text { House staff, medical } \\
\text { students, and ward nurses }\end{array}$ & Primary BSIs \\
\hline Miller (1996) & Pennsylvania USA & $\begin{array}{l}\text { Single centre; medical and } \\
\text { surgical wards }\end{array}$ & 'IV Therapy Team' & $\begin{array}{l}\text { House staff and nursing } \\
\text { personnel }\end{array}$ & PIVC-related infections \\
\hline Scalley (1992) & Colorado, USA & Single centre; hospital wide & 'IV Team' & 'Non-IVT' & Phlebitis \\
\hline Soifer (1998) & Illinois, USA & $\begin{array}{l}\text { Single centre; medical } \\
\text { inpatient service }\end{array}$ & 'IV team' & Medical house staff & PIVC-related complications \\
\hline $\begin{array}{l}\text { Tomford } \\
\text { (1984) }\end{array}$ & Ohio, USA & $\begin{array}{l}\text { Single centre; general } \\
\text { medical firms (inpatient and } \\
\text { outpatient units) }\end{array}$ & 'IV team' & Medical house staff & PIVC-related complications \\
\hline
\end{tabular}


A further limitation in this review was the unclear allocation of PIVC insertion to the VAS team, which made it difficult to ascertain the true benefit of VAS-inserted PIVCs for preventing failure. Tomford et al..$^{25}$ and Soifer et al. ${ }^{30}$ included patients whose catheters had been inserted by other health professionals to the VAS groups if the patient's PIVC had been maintained by the VAS team.

In addition, included studies were at risk of reporting bias as outcome data were collected by members of the VAS team, ${ }^{15,24}$ clinicians placing the catheters, ${ }^{16}$ or study investigators who were aware of the study allocation. ${ }^{24}$ Palefski et al. ${ }^{16}$ allowed nurses to self-evaluate their skill level and nominate themselves as a VAS. The outcome data for this study were collected by the nurse caring for the patient at the time the PIVC was removed, regardless of whether they had inserted the catheter. These nurses were not blinded to the inserter, therefore introducing the potential for reporting bias. Soifer et al. ${ }^{30}$ reported a lower rate of failure for VAS-inserted PIVCs, but this may be a result of the trained outcome assessor inspecting all PIVC sites for the VAS team but less than half of the PIVCs inserted by the medical officers. Scalley et al. ${ }^{24}$ did not identify the number of PIVCS inserted by the VAS team compared to other health professionals, making it difficult to determine the benefit of VAS-inserted PIVCs. A further limitation to this study was that the outcome measure of phlebitis was recorded by the VAS team, who were un-blinded to the inserting health professional. This therefore created a potential for ascertainment bias favouring the VAS team, with the potential of under- or over-reporting of phlebitis. Carr et al..$^{15}$ reported improvement in first-attempt PIVC insertion success during the first five months of establishing a VAS team; however, insertion attempts were self-reported, therefore introducing the risk of outcome reporting bias.

\section{Conclusion}

Use of a VAS for PIVC insertion to reduce PIVC failure is currently unsupported by high quality evidence. Well conducted RCTs to compare VAS with the generalist PIVC insertion model are required.

\section{DISCLOSURES}

Nicole Marsh's previous employer, Griffith University, received, on her behalf, investigator-initiated research grants and unrestricted educational grants from Becton Dickinson and Cardinal Health, and a consultancy payment provided to Griffith University from Becton Dickinson for clinical feedback related to catheter placement and maintenance (unrelated to the current project).

Emily Larsen's employer, Griffith University, received, on her behalf, a consultancy payment for an educational lecture, from $3 \mathrm{M}$ and an investigator-initiated grant-in-aid from Medtronic (now Cardinal Health) (unrelated to the current project).
Marie Cooke reports investigator-initiated research grants and speaker fees provided to Griffith University by vascular access product manufacturers (Baxter, Becton Dickinson, Entrotech Life Sciences) (unrelated to the current project).

Claire M. Rickard's employer, Griffith University, received, on her behalf, investigator-initiated research or educational grants from Becton Dickinson-Bard and Cardinal Health, and consultancy payments for educational lectures/expert advice from 3M, Becton Dickinson-Bard, BBraun (unrelated to the current project).

Joan Webster has nothing to declare.

\section{REFERENCES}

1. Sabri A, Szalas J, Holmes KS, Labib L, Mussivand T. Failed attempts and improvement strategies in peripheral intravenous catheterization. Biomed Mater Eng. 2012; 23(1-2): 93-108.

2. Marsh N, Webster J, Larsen E, Genzel J, Cooke M, Mihala G, et al. Expert versus generalist inserters for peripheral intravenous catheter insertion: a pilot randomised controlled trial. Trials 2018; 19(1): 564.

3. Bausone-Gazda D, Lefaiver CA, Walters SA. A randomized controlled trial to compare the complications of 2 peripheral intravenous catheterstabilization systems. J Infus Nurs 2010; 33(6): 371-84.

4. Dillon MF, Curran J, Martos R, Walsh C, Walsh J, Al-Azawi D, et al. Factors that affect longevity of intravenous cannulas: a prospective study. QJM 2008; $101(9):$ 731-5.

5. Wallis MC, McGrail M, Webster J, Marsh N, Gowardman J, Playford EG et al. Risk factors for peripheral intravenous catheter failure: a multivariate analysis of data from a randomized controlled trial. Infec Control Hosp Epidemiol. 2014; 35(1): 63-8.

6. Marsh N, Webster J, Larson E, Cooke M, Mihala G, Rickard CM. Observationa study of peripheral intravenous catheter outcomes in adult hospitalized patients: a multivariable analysis of peripheral intravenous catheter failure. J Hosp Med. 2018; 13(2): 83-9.

7. Abolfotouh MA, Salam M, Bani-Mustafa A, White D, Balkhy HH. Prospective study of incidence and predictors of peripheral intravenous catheterinduced complications. Ther Clin Risk Manag. 2014; 10: 993-1001.

8. Cicolini G, Bonghi AP, Di Labio L, Di Mascio R. Position of peripheral venous cannulae and the incidence of thrombophlebitis: an observational study. J Adv Nurs. 2009; 65(6): 1268-73.

9. Webster J, Osborne S, Rickard CM, Marsh N. Clinically-indicated replacement versus routine replacement of peripheral venous catheters. CDSR. 2019; (1).

10. López JG, Vilela AA, del Palacio EF, Corral JO, Martí CB, Portal PH. Indwell times, complications and costs of open vs closed safety peripheral intravenous catheters: a randomized study. J Hosp Infect. 2014; 86(2): 117-26.

11. Rickard CM, Ray-Barruel G. Peripheral intravenous catheter assessment: beyond phlebitis. Lancet Haematol. 2017; 4(9): e402-e3.

12. Carr PJ, Higgins NS, Cooke ML, Mihala G, Rickard CM. Vascular access specialist teams for device insertion and prevention of failure. CDSR. 2018; 20(3).

13. Robertson KJ. The role of the i.v. specialist in health care reform. J Intraven Nurs. 1995; 18(3): 130-44.

14. Hadaway L, Dalton L, Mercanti-Erieg L. Infusion teams in acute care hospitals: call for a business approach: an Infusion Nurses Society white paper. J Infus Nurs. 2013; 36(5): 356-60.

15. Carr PJ, Glynn RW, Dineen B, Kropmans TJ. A pilot intravenous cannulation team: an Irish perspective. Br J Nurs. 2010; 19(10): S19-27.

16. Palefski SS, Stoddard GJ. The infusion nurse and patient complication rates of peripheral-short catheters: a prospective evaluation. J Infus Nurs. 2001; 24(2): 113-23. 
17. Carr PJ, Rippey JC, Cooke ML, Higgins NS, Trevenen M, Foale A, et al. From insertion to removal: A multicenter survival analysis of an admitted cohort with peripheral intravenous catheters inserted in the emergency department. Infec Control Hosp Epidemiol. 2018; 39(10): 1216-21.

18. Dougherty L. The benefits of an iv team in hospital practice. Professional Nurse (London, England). 1996; 11(11): 761-3.

19. Kelly LJ, Buchan E, Brown A, Tehrani Y, Cowan D. Exploring how the development of a nurse-led vascular access service has benefited patients. Nurs Times. 2009; 105(24): 16-8.

20. Green $B N$, Johnson $C D$, Adams A. Writing narrative literature reviews for peer-reviewed journals: secrets of the trade. J Chiropr Med. 2006; 5(3): 101-17.

21. Moher D, Liberati A, Tetziaff J, Altman DG, The PRISMA Group. Preferred reporting items for systematic reviews and meta-analyses. PLoS Med. 2009; 6(7): e1000097.

22. Hong QN, Pluye P, Fábregues S, Bartlett G, Boardman F, Cargo M, et al. Mixed methods appraisal tool (MMAT). Version 2018. 208.

23. Hunter MR. Development of a vascular access team in an acute care setting. J Infus Nurs. 2003; 26(2): 86-91.

24. Scalley RD, Van CS, Cochran RS. The impact of an i.v. team on the occurrence of intravenous-related phlebitis. A 30-month study. J Intraven Nurs. 1992; 15(2): 100-9.

25. Tomford JW, Hershey CO, MCLaren CE, Porter DK, Cohen DI. Intravenous therapy team and peripheral venous catheter-associated complications. A prospective controlled study. Arch Intern Med. 1984; 144(6): 1191-4.

26. Bosma $T L$, Jewesson PJ. An infusion program resource nurse consult service: our experience in a major Canadian teaching hospital. J Infus Nurs. 2002; 25(5): 310-5

27. da Silva GA, Priebe S, Dias FN. Benefits of establishing an intravenous team and the standardization of peripheral intravenous catheters. J Infus Nurs. 2010; 33(3): 156-60.

28. Meier PA, Fredrickson M, Catney M, Nettleman MD. Impact of a dedicated intravenous therapy team on nosocomial bloodstream infection rates. Am J Infect Control. 1998; 26(4): 388-92.

29. Miller JM, Goetz AM, Squier C, Muder RR. Reduction in nosocomial intravenous device-related bacteremias after institution of an intravenous therapy team. J Intraven Nurs. 1996; 19(2): 103-6.

30. Soifer NE, Borzak S, Edlin BR, Weinstein RA. Prevention of peripheral venous catheter complications with an intravenous therapy team: a randomized controlled trial. Arch Intern Med. 1998; 158(5): 473-7.

31. Castillo MI, Larsen E, Cooke M, Marsh NM, Wallis MC, Finucane J, et al. Integrated versus non-integrated peripheral intravenous catheter. Which Is the most effective system for peripheral intravenous catheter Management?(The OPTIMUM study): a randomised controlled trial protocol. BMJ Open. 2018; 8(5): e019916.

32. Marsh N, Larsen E, Genzel J, Mihala G, Ullman AJ, Kleidon T, et al. A novel integrated dressing to secure peripheral intravenous catheters in an adult acute hospital: a pilot randomised controlled trial. Trials. 2018; 19(1): 596.

33. Rickard CM, Marsh N, Webster J, Runnegar N, Larsen E, McGrail MR, et al. Dressings and securements for the prevention of peripheral intravenous catheter failure in adults (SAVE): a pragmatic, randomised controlled, superiority trial. Lancet. 2018; 392(10145): 419-30.

34. Marsh N, Webster J, Flynn J, Mihala G, Hewer B, Fraser J, et al. Securement methods for peripheral venous catheters to prevent failure: a randomised controlled pilot trial. JVA. 2015; 16(3): 237-44.

35. Holder MR, Stutzman SE, Olson DM. Impact of ultrasound on short peripheral intravenous catheter placement on vein thrombosis risk. J Infus Nurs. 2017; 40(3): 176-82

36. Joing S, Strote S, Caroon L, Wall C, Hess J, Roline C, et al. Ultrasoundguided peripheral IV placement. N Engl J Med. 2012; 366(25): e38.

37. Anderson NR. Midline catheters: the middle ground of intravenous therapy administration. J Infus Nurs. 2004; 27(5): 313-21.
38. Chopra V, Flanders SA, Saint S, Woller SC, O'Grady NP, Safdar N, et al. The Michigan appropriateness guide for intravenous catheters (MAGIC): results from a multispecialty panel using the RAND/UCLA appropriateness method. Ann Intern Med. 2015; 163(6_Supplement): S1-S40.

39. Deutsch GB, Sathyanarayana SA, Singh N, Nicastro J. Ultrasound-guided placement of midline catheters in the surgical intensive care unit: a costeffective proposal for timely central line removal. J Surg Res. 2014; 191(1): $1-5$. 